\title{
Enteral nutrition after bone marrow transplantation
}

\author{
A Papadopoulou, A MacDonald, M D Williams, P J Darbyshire, I W Booth
}

\begin{abstract}
Nutritional insult after bone marrow transplantation (BMT) is complex and its nutritional management challenging. Enteral nutrition is cheaper and easier to provide than parenteral nutrition, but its tolerance and effectiveness in reversing nutritional depletion after BMT is poorly defined. Nutritional status, wellbeing, and nutritional biochemistry were prospectively assessed in 21 children (mean age 7.5 years; 14 boys) who received nasogastric feeding after BMT (mean duration 17 days) and in eight children (mean age 8 years, four boys) who refused enteral nutrition and who received dietetic advice only.
\end{abstract}

Enteral nutrition was stopped prematurely in eight patients. Greater changes in weight and mid upper arm circumference were observed in the enteral nutrition group, while positive correlations were found between the duration of feeds and increase in weight and in mid upper arm circumference. Vomiting and diarrhoea had a similar incidence in the two groups, while fever and positive blood cultures occurred more frequently in the dietetic advice group. Diarrhoea occurring during enteral nutrition was not associated with fat malabsorption, while carbohydrate malabsorption was associated with rotavirus infection only. Enteral feeding did not, however, affect bone marrow recovery, hospital stay, general wellbeing, or serum albumin concentrations. Hypomagnesaemia, hypophosphataemia, zinc and selenium deficiency were common in both groups. In conclusion, enteral nutrition, when tolerated, is effective in limiting nutritional insult after BMT. With existing regimens nutritional biochemistry should be closely monitored in order to provide supplements when required.

(Arch Dis Child 1997;77:131-136)

Keywords: bone marrow transplantation; enteral nutrition; parenteral nutrition

Bone marrow transplantation (BMT) has been shown to have a profound effect on nutritional status and nutritional biochemistry in children. Nutrient intake is impaired by nausea, vomiting, dysgeusia, anorexia, and multiple organ dysfunction. ${ }^{1}$ BMT in children is associated with diarrhoea and protein losing enteropathy, ${ }^{2}{ }^{3}$ hypoalbuminaemia, ${ }^{34}$ and trace element deficiency. ${ }^{5}$ Malnutrition has been shown to be associated with poorer outcomes in many types of malignancy, although the causal nature of this relationship is unproved. ${ }^{6}$ In children with leukaemia, malnutrition is associated with a higher infection rate, ${ }^{8}$ while zinc depletion after BMT is associated with more frequent episodes of fever of longer duration. ${ }^{5}$ There is therefore a pressing need to prevent malnutrition, by providing appropriate nutritional support to this group of patients. Although parenteral nutrition has been considered to be the method of choice for providing nutritional support to these patients, ${ }^{9}{ }^{10}$ it is recognised that enteral nutrition has a beneficial effect on gut mucosal barrier function in experimental animals ${ }^{11}$ and in humans, ${ }^{12}$ and is also cheaper ${ }^{13}$ and easier to provide than parenteral nutrition. Its tolerance and efficacy in children undergoing BMT is, however, still disputed. Some investigators consider that 'forced enteral feeding' is an unacceptable option for nutritional support in young children with cancer, ${ }^{14}$ while others have shown enteral nutrition to be well tolerated by children undergoing treatment for malignancies. ${ }^{15}$ Studies in adults undergoing BMT have also shown supplementary enteral nutrition to be feasible. ${ }^{1316} \mathrm{~A}$ recent anecdotal report in a child undergoing BMT claimed good tolerance of long term enteral feeding after BMT. ${ }^{17}$ We were not aware, however, of any prospective studies assessing the tolerance and efficacy of enteral nutrition in children undergoing BMT. The aim of the study was therefore to assess prospectively the tolerance of enteral nutrition by children undergoing $\mathrm{BMT}$, and its efficacy in preventing nutritional insult caused by BMT.

\section{Patients and methods}

\section{PATIENTS}

Enteral nutrition was offered to 29 patients undergoing BMT. Twenty one patients (mean age 7.5 years; 14 boys) elected to receive enteral nutritional support while in hospital for BMT, and eight children (mean age 8 years, four boys) refused. Outcomes in these two groups were compared. Table 1 shows the characteristics of the patients. The study was approved by the ethical committee of South Birmingham Health Authority. Informed consent for taking part in the study was obtained from patients or, where appropriate, their parents. 
Table 1 Clinical characteristics of patients

\begin{tabular}{|c|c|c|c|}
\hline & $\begin{array}{l}\text { Enteral nutrition } \\
(n=21)\end{array}$ & $\begin{array}{l}\text { Dietetic advice } \\
(n=8)\end{array}$ & $p$ Value \\
\hline Mean (SD) age (years) & $7.5(4)$ & $8(4)$ & 0.6 \\
\hline \multicolumn{4}{|l|}{ Mean (SD) $\mathrm{z}$ scores on admission } \\
\hline Weight for height & $0.34(0.9)$ & $0.83(0.7)$ & 0.2 \\
\hline Mid arm circumference & $-0.04(0.7)$ & $0.13(0.7)$ & 0.6 \\
\hline \multicolumn{4}{|l|}{ Sex } \\
\hline Boys & 14 & 4 & \\
\hline Girls & 7 & 4 & \\
\hline \multicolumn{4}{|l|}{ Indications for BMT } \\
\hline Acute leukaemia & 12 & 2 & \\
\hline Solid tumours & 1 & 2 & \\
\hline Aplastic anaemia & 1 & 1 & \\
\hline$\beta$-Thalassaemia & 5 & 2 & \\
\hline Wiskott-Aldrich syndrome & 1 & - & \\
\hline Sickle cell anaemia & - & 1 & \\
\hline Myelodysplasia & 1 & - & \\
\hline \multicolumn{4}{|l|}{ Conditioning regimens } \\
\hline Cyclophosphamide and total body irradiation & 8 & 2 & \\
\hline Cyclophosphamide and busulphan & 8 & 4 & \\
\hline Idarubicin and total body irradiation & 5 & - & \\
\hline Melphalan & - & 2 & \\
\hline
\end{tabular}

METHODS

Anthropometry

Serial measurements of nutritional status were carried out in patients while in hospital for BMT. Height was measured on admission and on discharge (Harpenden stadiometer), weight was measured daily (SECA, Germany), and mid upper arm circumference was measured weekly with an unstretchable tape measure (Holtain Instruments Ltd, Wales) by the same observer (AP). Height, weight for height, and mid arm circumference were expressed as $\mathrm{z}$ scores. American reference data were used as reference $\mathrm{z}$ scores. ${ }^{18}$

\section{Clinical observations}

Episodes of vomiting (more than twice a day for more than two days), diarrhoea (more than three loose stools per day for more than two days), and fever $\left(>38^{\circ} \mathrm{C}\right.$ per day for more than one day) were recorded.

Haematology, biochemistry, and stool analyses Total white cell, lymphocyte, and platelet counts were checked daily. Serial serum biochemical analyses (urea, creatinine, albumin, electrolytes, liver function tests) were carried out twice a week (by reflectance photometry on a Kodak Ektachem 700XR). Serum calcium, phosphate, magnesium, and plasma zinc, selenium, and copper were carried out once every week (minerals by reflectance photometry on a Kodak Ektachem 700XR; trace elements by atomic absorption). Diarrhoea during enteral nutrition was investigated in three patients (stool reducing substances, chromatography, and steatocrit ${ }^{19}$ ).

\section{Wellbeing}

The general wellbeing of the patients was assessed weekly using the Lansky performance scoring system. ${ }^{20}$

\section{Indications for enteral nutrition}

The indications for enteral nutrition were weight loss of more than $5 \%$ of the admission weight or a greater than $10 \%$ decrease in mid upper arm circumference, or both. The sole exclusion criterion was the presence of oral mucositis at the start of nutritional support. Twenty one children gave their permission to start supplementary enteral nutrition, while eight patients were upset by the idea of having a nasogastric tube and elected instead to follow dietary counselling.

\section{Enteral nutrition}

Enteral nutrition was provided through a nasogastric tube via a Kangaroo 330 pump (Sherwood Medical Industries Ltd). Nutrison Paediatric (Nutricia), which provided 0.00418 $\mathrm{MJ} / \mathrm{ml}$ (1 $\mathrm{kcal} / \mathrm{ml}$ ), was given to children weighing up to $20 \mathrm{~kg}$, while Fortisip (Nutricia), which provided $0.00627 \mathrm{MJ} / \mathrm{ml}(1.5 \mathrm{kcal} / \mathrm{ml})$, was given to children weighing $>20 \mathrm{~kg}$. One patient who developed diarrhoea for more than three days, and another one who received enteral nutrition after 43 days of parenteral nutrition due to gut graft versus host disease were given Pepdite $2^{+}$(SHS).

The volume of the feed was individual to each patient. The total daily intake was planned to provide $100 \%$ of estimated average requirements for energy, based on admission weight, which was appropriate for a physical activity level of $1.4 .^{21}$ Overnight nasogastric feeding was scheduled to provide half of the daily requirement within seven days of starting. Feeding was introduced at a rate of $10 \mathrm{ml}$ per hour, increasing by $10 \mathrm{ml}$ per hour per day if tolerated. When the total scheduled volume was achieved, the infusion rate was increased in order to provide the same volume during 10 to 14 hours overnight. Oral intake was encouraged during the day. Overnight feeds were stopped when patients achieved 100\% of estimated average requirements for energy by the oral route.

The amounts of trace elements and minerals provided in $100 \mathrm{ml}$ of Nutrison Paediatric (Fortisip) were as follows: zinc 0.6 (1.5) mg; copper 87 (230) $\mu \mathrm{g}$; selenium 2.33 (6.4) $\mu \mathrm{g}$; and magnesium 20 (30) $\mathrm{mg}$.

\section{Dietary counselling}

Dietary counselling was provided several times a week until the discharge by an experienced paediatric dietitian in order to promote a high energy oral intake. Oral energy supplements (Maxijul, Calogen; SHS) were added to the drinks, and sip feeds encouraged.

\section{STATISTICS}

Differences in the nutritional status before compared with after enteral nutrition/dietetic counselling as well as differences in serum minerals before compared with during enteral nutrition/dietetic counselling were analysed using paired Student's $t$ test. Differences in the $z$ scores of the anthropometry indices between the study group and the controls were analysed using non-paired $t$ test. Mann-Whitney test was used to analyse differences in plasma trace elements before compared with during enteral nutrition/dietetic counselling as well as differences in bone marrow recovery, hospital stay, and play performance between the two groups. Simple linear regression analysis was used to describe the relation between the duration of 


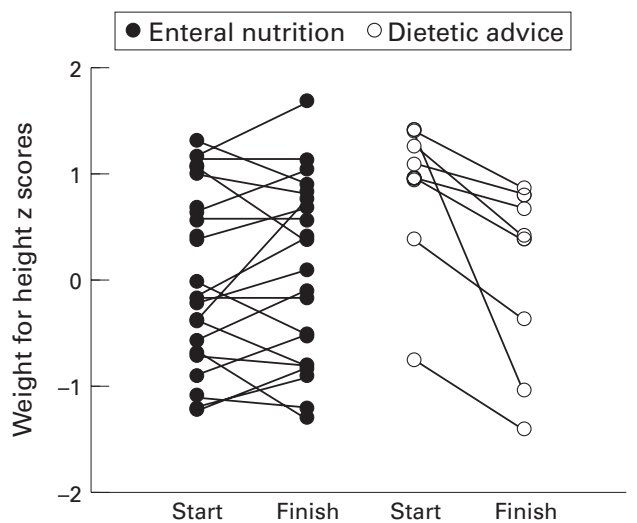

Figure 1 Changes in weight for height $z$ scores during enteral nutrition $(n=21)$ or dietetic counselling $(n-8)$. Enteral nutrition was associated with a non-significant improvement $(p=0.4)$, while dietetic counselling with a non-significant deterioration $(p=0.07)$ in the nutritional status.

feeds and the improvements in the nutritional status. Fisher's exact test was used for the comparisons of the incidence of vomiting, diarrhoea, and fever as well as positive blood cultures between the two groups.

\section{Results}

Poor nutrition was common, even before transplantation: 13 of the 29 patients had a $\mathrm{z}$ score for at least one anthropometric variable (weight for height, mid arm circumference, or height for age $\mathrm{z}$ score) less than -1 . Wasting (weight for height or mid arm circumference, or both, z score <-1) affected two of the 29 patients, while poor linear growth (height for age $\mathrm{z}$ score $<-1$ ) affected 11 of the 29 patients.

Vomiting, diarrhoea, and fever after BMT had a similar incidence in malnourished and non-malnourished patients occurring in six, four, and seven of the 13 malnourished patients respectively, and in two, four, and four of the 16 well nourished ones respectively $(p=0.09 ; p=1$; and $p=0.1$ respectively). Similarly, there was no difference in bone marrow recovery between the two groups. Hospital stay tended to be longer, however, in the malnourished patients without the difference reaching statistical significance: median (range) days of hospital stay were $33(20-266)$ v 27.5 (14-43) respectively; $\mathrm{p}=0.09$.

Of the 21 patients who received enteral nutrition, two patients were discharged on home enteral nutrition and 11 reached sufficient oral intake during the daytime and stopped the overnight feeds after a mean duration of 22 days. Eight patients were treatment failures. Seven of them vomited the tube after a mean duration of 10 days of enteral nutrition, while one stopped feeding after eight days of enteral nutrition because of diarrhoea. Six of these eight children were switched to parenteral nutrition.

The mean (SD) energy intake provided by overnight nasogastric feeding was $3.43(0.89)$ $\mathrm{MJ} /$ day (820 (212) $\mathrm{kcal} /$ day), which provided a mean (SD) of $48(6.5) \%$ of the estimated average requirements for energy. Oral intake during the daytime was not measured.
Nasogastric feeding maintained nutritional status after BMT, while dietetic advice alone was associated with a non-significant deterioration in the nutritional status (see fig 1): mean (SD) weight for height and mid arm circumference $\mathrm{z}$ scores at the start and finish of enteral nutrition were $0.01(0.8) v 0.13(0.8)$ respectively $(\mathrm{p}=0.4)$; and $0.05(0.7) \quad v 0.06(0.8)$ respectively $(p=0.3)$; weight for height and mid upper arm circumference $\mathrm{z}$ scores at the start and finish of dietetic advice were $0.8(0.7) v$ 0.04 (0.9), $(\mathrm{p}=0.07)$; and $0.13(0.7) v-0.35$ (0.8) respectively $(p=0.2)$. Furthermore, significantly less deterioration in the weight and mid upper arm circumference were shown in the group who received enteral nutrition compared with dietetic advice alone: mean (SD) weight for height $\Delta \mathrm{z}$ scores (differences between $\mathrm{z}$ scores at the start from those at the end of enteral nutrition/dietetic counselling) were $0.08(0.4) v-0.79(0.7)$ respectively $(\mathrm{p}=0.0005) ;$ mid upper arm circumference $\Delta \mathrm{z}$ scores were $0.09(0.5) v-0.49(0.6)$ respectively $(p=0.01)$. The duration of feeds was the major factor determining the size of the nutritional response. Significant positive correlations were found between the duration of enteral nutrition and the improvements in weight $(r=0.75 ; \mathrm{p}<0.0001$; see fig 2$)$ and mid upper arm circumference $(r=0.74 ; \mathrm{p}=0.0004$; see fig 3).

The incidence or the duration of vomiting and diarrhoea was not significantly different

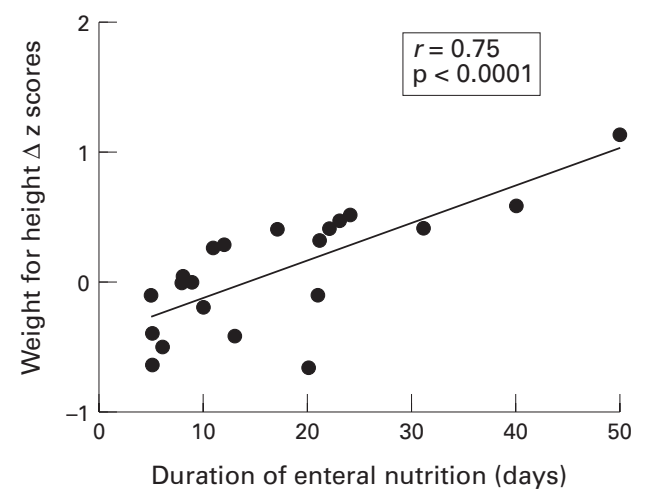

Figure 2 Correlation between the improvement in weight and the duration of feeds. The improvement in weight was correlated with the duration of feeds $(r=0.75 ; p<0.0001)$.

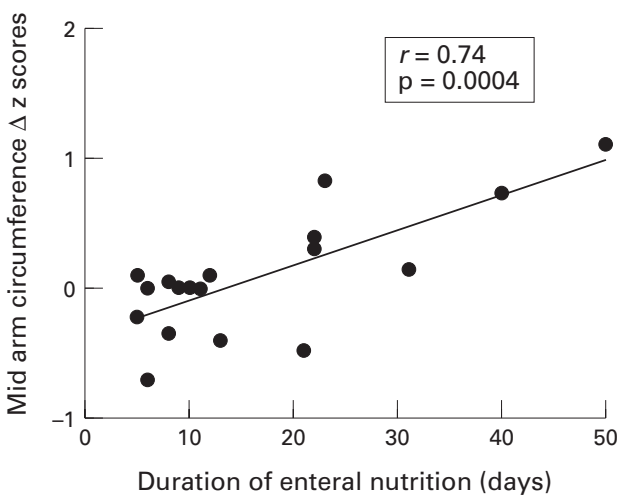

Figure 3 Correlation between the improvement in mid arm circumference and the duration of feeds. The improvement in mid arm circumference was correlated with the duration of feeds $(r=0.74 ; p=0.0004)$. 
Table 2 Clinical outcomes and gastrointestinal complications after BMT

\begin{tabular}{lccl}
\hline & $\begin{array}{c}\text { Enteral nutrition } \\
(n=21)\end{array}$ & $\begin{array}{c}\text { Dietetic advice } \\
(n=8)\end{array}$ & $p$ Value \\
\hline Incidence (\%) & & & \\
$\quad$ Vomiting & $4(19)$ & $4(50)$ & 0.2 \\
$\quad$ Diarrhoea & $4(19)$ & $4(50)$ & 0.2 \\
$\quad$ Fever & $5(24)$ & $6(75)$ & 0.03 \\
Mean (SD) duration (days) & & & \\
$\quad$ Vomiting & $6.5(2.1)$ & $10(2.3)$ & 0.06 \\
$\quad$ Diarrhoea & $4.2(1.5)$ & $11(12)$ & 0.3 \\
Fever & $3.4(1.1)$ & $5.2(3.8)$ & 0.6 \\
$\quad$ Bone marrow recovery & $13.6(4.0)$ & $12.2(3.4)$ & 0.5 \\
$\quad$ Hospital stay & $27.7(6.8)$ & $31.7(12.5)$ & 0.4 \\
Positive blood cultures (\%) & $1(5)$ & $3(37)$ & 0.05 \\
Mean (SD) Lansky performance score (points) & $65(17)$ & $60(10)$ & 0.4 \\
\hline & & & \\
\hline
\end{tabular}

between the two groups, while fever and positive blood cultures were fewer in patients receiving enteral nutrition (see table 2). Furthermore, the provision of enteral nutrition did not influence clinical outcomes: hospital stay, bone marrow recovery, or the general wellbeing of patients after BMT were not different between the two groups (see table 2).

A specific cause was identified in only two cases of diarrhoea, during enteral nutrition: rotavirus infection complicated later by graft versus host disease in one, and cutaneous graft versus host disease in another patient. In three of the four enteral nutrition patients with diarrhoea, stool was checked in order to exclude carbohydrate or fat malabsorption, or both. Positive reducing substances were found in only one case of diarrhoea (rotavirus infection), while faecal steatocrit was normal in all three patients.

Serum albumin concentrations after BMT were comparable in patients who received enteral nutrition and those who did not: mean (SD) serum albumin (g/l) were 34.4 (2.4) v 36.2 (2.8), respectively; $\mathrm{p}=0.09$. Furthermore, supplementary enteral nutrition did not prevent other deficiencies of some important micronutrients (see table 3 ).

\section{Discussion}

This study showed that poor nutritional status was common even before BMT, and occurred in about half of the patients. We showed that supplementary enteral nutrition was not only feasible in children undergoing BMT, but was associated with fewer febrile episodes and positive blood cultures than standard dietetic counselling alone. Furthermore, it was more effective in preventing deterioration of nutritional status after BMT and significant positive correlations were shown between the duration of feeds and improvements in nutritional status. Nasogastric feeding was not associated with excess gastrointestinal disturbances or with overt nutrient malabsorption. However, enteral nutrition did not prevent biochemical deficiency of a number of nutrients.
One limitation of this study was that it was not randomised. A randomised trial was considered to be unjustified in this group of patients, as previous studies by us and others in children with malignancies have shown that nutritional status deteriorates during chemotherapy if no nutritional support is provided. ${ }^{1522} 23$ We therefore compared the response of patients receiving enteral nutrition, with patients who fulfilled the criteria for providing nutritional support, but who declined nasogastric feeding and instead followed the dietetic instructions for an oral intake of high energy. Another limitation was the absence of data on the oral intake of the patients. This was due mainly to large interindividual and intraindividual variation in dietary intake in these patients making any conclusions based on data on food intake likely to be misleading.

Malnutrition is a frequent complication of the treatment of malignancy ${ }^{24}$ and has implications for disease outcome. ${ }^{672526}$ The deterioration in nutritional status during treatment has been confirmed by us and by others in prospective, controlled studies where patients with malignancies were randomised to receive either parenteral nutrition, ${ }^{14}$ or enteral nutrition, ${ }^{15}$ versus no support. In both studies a significant weight loss was observed in controls. Two other trials of enteral feeding, although uncontrolled, showed that nasogastric feeding was associated with an improvement in weight in children with leukaemia, ${ }^{27}$ and children with unspecified malignancy. ${ }^{28}$ Some clinicians have therefore recommended that nutritional support be a routine part of treatment in childhood cancer. ${ }^{29-31}$

Until recently, parenteral nutrition was the option of choice for providing nutritional support in this group of patients. The benefits of parenteral nutrition in children with malignancy are disputed, however. A number of investigators have claimed benefit with respect to reversing malnutrition, increasing albumin levels, and an earlier recovery of marrow function, ${ }^{30-33}$ while others showed no benefits either in recovery from myelosuppression, or in infection rates. ${ }^{34}$

Enteral nutrition is cheaper and safer than parenteral nutrition..$^{35}$ In patients undergoing BMT, we are aware of two studies assessing enteral nutrition prospectively. A randomised trial in adults undergoing BMT showed fewer complications in patients receiving enteral nutrition compared with parenteral nutrition. ${ }^{13}$ Mulder et al reported a lower incidence of diarrhoea in patients receiving enteral nutrition than in those given parenteral nutrition alone. ${ }^{16}$ We know of no prospective studies assessing the tolerance and efficacy of enteral nutrition in children undergoing BMT. A recent anecdotal

Table 3 Changes in nutritional biochemistry after BMT

\begin{tabular}{lllll}
\hline & $\begin{array}{l}\text { Mean }(S D) \text { before } \\
B M T\end{array}$ & $\begin{array}{l}\text { Minimum }(S D) \text { during } \\
\text { dietetic advice }\end{array}$ & $\begin{array}{l}\text { Mean }(S D) \text { before } \\
B M T\end{array}$ & $\begin{array}{l}\text { Minimum }(S D) \text { during } \\
\text { enteral nutrition }\end{array}$ \\
\hline Plasma zinc $(\mu \mathrm{mol} / \mathrm{l})$ & $11.8(5.0)$ & $12.0(3.8)$ & $12.9(3.1)$ & $11.2(2.7)$ \\
Plasma selenium $(\mu \mathrm{g} / \mathrm{l})$ & $53.2(11.0)$ & $46.0(10.8)$ & $59.0(11.8) \ddagger$ & $54.0(9.8) \ddagger$ \\
Serum phosphate $(\mathrm{mmol} / \mathrm{l})$ & $1.4(0.1)^{\star}$ & $0.9(0.3)^{\star}$ & $1.4(0.3)$ & $1.2(0.3)$ \\
Serum magnesium $(\mathrm{mmol} / \mathrm{l})$ & $0.8(0.2)$ & $0.6(0.2)$ & $0.7(0.1) \dagger$ & $0.6(0.1) \dagger$ \\
\hline
\end{tabular}

$p$ Values: ${ }^{\star} p=0.006 ; \dagger p=0.0005 ; \ddagger p=0.07$; all other values were not significant. 
report, however, claimed that long term (duration of 300 days) enteral nutrition via a gastrostomy button was feasible in a child undergoing BMT. ${ }^{17}$ It was associated with an improvement in the nutritional status of the child and maintenance of normal visceral protein stores.

There is uncertainty about the type of the feed which should be used after BMT. A variety of feeds have been used in studies in adults. ${ }^{37} 38$ Semihydrolysed diets have been shown to protect against the sequelae of abdominal radiotherapy in adults, ${ }^{39}$ while conversely, standard chow had advantages over elemental diet in rats receiving methotrexate. ${ }^{40}$ Donaldson et al claimed successful management of radiation enteritis with a low residue, low fat and gluten, lactose, and cows' milk protein free diet. ${ }^{24}$ It is not clear from that study, however, whether the improvement was due to the specific dietary manipulations or just to nutritional repletion. Halton et al reported a low frequency of transient malabsorption in children treated for acute lymphoblastic leukaemia. ${ }^{41}$ In our study, we showed that a diet containing lactose and cows' milk protein was well tolerated by most of the patients without any signs of nutrient malabsorption.

The cause and implications of the mineral depletion seen after BMT are not entirely clear. It is possible, however, that weight gain in patients receiving enteral nutrition was limited because of micronutrient insufficiency. Hypomagnesaemia has been reported to be associated with chemotherapy with cisplatin, ${ }^{42}$ as well as a combination of cisplatin and 5-flurouracil due to an increased loss of minerals with urine.$^{43}$ In children with Crohn's disease, magnesium loss in stools is observed, even during nutritional support, and has been attributed to absorptive defects in the inflamed intestine. ${ }^{44}$ In our study, however, hypomagnesaemia occurred irrespective of diarrhoea, supporting the possibility of a number of other factors in producing mineral deficiency after BMT. A recent study in critically ill patients with major trauma showed increased urinary excretion of zinc, selenium, and copper within a week after injury. ${ }^{45}$ In BMT adult patients, biochemical zinc depletion was observed before, but not after, BMT. ${ }^{46}$ The various adverse sequelae of trace element and mineral deficiencies indicate that early detection and treatment in this group of sick patients is required. ${ }^{47}$

In conclusion, enteral nutrition, when tolerated, is effective in preventing deterioration of nutritional status of children undergoing BMT and has a number of other benefits, including less fever and positive blood cultures. Standard feeding regimens do not prevent trace element and mineral deficiencies. Nutritional biochemistry therefore should be closely monitored during nutritional support in order to provide supplements when required.

The authors wish to thank the nursing staff of the BMT Unit for their contribution to the study; Ms Karen Rose, the play their contribution to the study; Ms Karen Rose, the play
specialist of the BMT Unit for undertaking the weekly play perspecialist of the BMT Unit for undertaking the weekly play per-
formance assessments; and Alison French and Bridget Lambert formance assessments; and Alison French and Britians who supervised enteral nutrition.

The study was sponsored by the Children's Hospital Bone Marrow Transplant Research Special Funds.
Martudy was sponsored by the Children's
1 Day DL, Carpenter BLM. Abdominal complications in pediatric bone marrow transplant recipients. Radiographics 993;13:1101-12

2 Weisdorf SA, Salati JA, Longsdorf NKC, Sharp HL. Graftversus-host disease of the intestine: a protein losing enteropathy characterised by faecal $\alpha_{1}$-antitrypsin. Gastroenterology 1983;85:1076-81.

3 Papadopoulou A, Lloyd DR, Williams MD, Darbyshire PJ, Booth IW. Gastrointestinal and nutritional consequences of bone marrow transplantation. Arch Dis Child 1996;75:20813.

4 Guiot HFL, Iemond J, Klasen E, et al. Protein loss during acute graft versus host disease: diagnostic and clinical significance. Eur $\mathcal{F}$ Haematol 1987;38:187-96.

5 Papadopoulou A, Nathavitharana K, Williams MD, et al. Diagnosis and clinical associations of zinc depletion following bone marrow transplantation. Arch Dis Child 1996;74:328-31.

6 Donaldson SS, Welsey MN, Dewys WD, et al. A study of the nutritional status of paediatric cancer patients. Am $\mathcal{F}$ Dis Child 1981;135:1107-12

7 van Eys J. Nutrition and cancer: physiological interrelationships. Annu Rev Nutr 1985;5:435-61.

8 Taj MM, Pearson AD, Mumford DB, Price L. Effect of nutritional status on the incidence of infection in childhood cancer. Pediatr Hematol Oncol 1993;10:283-7.

9 Apelgren KN, Wilmore DW. Parenteral nutrition: is it ontologically logical? A response. F Clin Oncol 1981;2:539-44.

10 Weisdorf S, Holland C, Sharp HL. Total parenteral nutrition in bone marrow transplantation: a clinical evaluation. F Pediatr Gastroenterol Nutr 1981;3:95-100.

11 Inoue S, Epstein MD, Alexander JW, et al. Prevention of yeast translocation across the gut by a single enteral feeding

12 Moore FA, Moore EE, Jones TN, et al. TEN versus TPN following major torso trauma: reduced septic morbidity. $\mathcal{f}$ following major torso tra
Trauma 1989;29:916-23.

13 Szeluga PJ, Stuart RK, Brookmeyer R, et al. Nutritional support of bone marrow transplant recipients: a prospective, randomised trials comparing total parenteral nutrition to an enteral feeding program. Cancer Res 1987;47:330916.

14 Rickard KA, Baehner RL, Coates TD, et al. Supportive nutritional intervention in pediatric cancer. Cancer Res 1982;42(suppl):766-73.

15 Smith DE, Handy DJ, Holden CE, et al. An investigation of supplementary nasogastric feeding in malnourished children undergoing treatment for malignancy: results of a pilot study. Fournal of Human Nutrition and Dietetics 1992; 5:85-91.

16 Mulder POM, Bouman JG, Gietema JA, et al. Hyperalimentation in autologous bone marrow transplantation for solid tation in autologous bone marrow

17 Ringwald-Smith K, Krance R, Stricklin L. Enteral nutrition support in a child after bone marrow transplantation. Nutrition in Clinical Practice 1995;10:140-3.

18 Frisancho AR. New norms of upper limb fat and muscle areas for assessment of nutritional status. Am $\mathcal{F}$ Clin Nutr 1981;34:2540-5

19 Rawasdeh MO, Lloyd DR, Puntis JWL, et al. Using the steatocrit to determine optimal fat content in modular feeds. Arch Dis Child 1992;67:608-12.

20 Lansky SB, List MA, Lansky LL, et al. The measurement of performance in childhood cancer patients. Cancer 1987;60: 1651-6.

21 Department of Health. Dietary reference values for food energy and nutrients for the United Kingdom. London: COMA, 1987. (Report on Health and Social Subjects 41.)

22 Rickard KA, Grosfeld JL, Kirksey A, et al. Reversal of protein-energy malnutrition in children during treatment of advanced neoplastic disease. Ann Surg 1979;190:771-8.

23 Rickard KA, Kirksey A, Baehner RL, et al. Effectiveness of enteral and parenteral nutrition in the nutritional management of children with Wilms' tumor. Am f Clin Nutr 1980; 33:2622-9.

24 Donaldson SS. Nutritional support as an adjust to radiation therapy. F Parenter Enteral Nutr 1984;8:302-10.

25 Merritt RJ, Kalsch M, Roux LD, et al. Significance of hypoalbuminaemia in pediatric oncology patients. $\mathcal{F}$ Parenter Enteral Nutr 1983;9:303-6.

26 van Eys J. The pathophysiology of undernutrition in the child with cancer. Cancer 1986;8:1874-80.

27 Goyens P, Otten J. Problemes nutritionels crees par les traitements anticancereux chez l' enfant. Rev Med Brux 1983;4:333-7.

28 Nico JJ, Ruymann FB, Nicol SJ. Nutritional support of pediatric oncology patients: identification of specific groups at increases risk. Proceedings of the 19th Annual Meeting of the International Society of Pediatric Oncology (SIOP), Jerusalem 1987.

29 Lukens JN. The use of nutritional therapy. Am f Pediatr Hematol Oncol 1984;6:261-5.

30 Rickard KA, Becker MC, Loghmani ES, et al. Effectiveness of two methods of parenteral nutrition support in improving muscle mass of children with neuroblastoma or Wilms' tumor. Cancer 1989;64:116-25.

31 Rickard KA, Godshall BJ, Loghmani ES, et al. Integration of nutrition support into oncologic treatment protocols for high and low nutritional risk children with Wilms' tumor. Cancer 1989;64:491-509.

32 Hays DM, Merritt RJ, White L, Siegel SE. Effect of total parenteral nutrition on marrow recovery during induction therapy for acute nonlymphotic leukaemia in childhood. Med Pediatr Oncol 1983;11:134-40. 
33 van Eys J, Copeland EM, Cangir A, et al. A clinical trial of hyperalimentation in children with metastatic malignancies. Med Pediatr Oncol 1980;8:63-73.

34 Shamberger RD, Pizzo PA, Goodgame JT, et al. The effect of total parenteral nutrition on chemotherapy-induced myelosuppression. Am F Med 1983;74:40-8

35 Payne-James J, deGara C, Grimble G, et al. Nutritional support in hospitals in the United Kingdom: national survey 1988. Health Trends 1990;22:9-13.

36 Elia M. Artificial nutritional support. Med Interna 1990;82 3392-6.

37 Johnston IDA, Wright PD, Lennard TWJ, et al. Malnutrition and cancer. Clin Oncol 1981;7:83-91.

38 Block JB, Chlebowski RT, Herrold JW. Continuous enteric alimentation with a blenderized formula in cancer cachexia. Clin Oncol 1981;7:93-8.

39 Bounous G, le Bel E, Shuster J. Dietary protection during radiation therapy. Strahletherapie 1975;149:476-183.

40 McAnena OJ, Rossi M, Mehta BM, Daly JM. Alteration of methatrexate metabolism in rats by administration of an methatrexate metabolism in rats by

41 Halton J Atkinson SA, Bradley C, et al Acute lymphoid leukemia. No evidence of consistent chemotherapy in- duced intestinal malabsorption. Am $\mathcal{f}$ Pediatr Hematol Oncol 1993;15:271-6.

42 Fossa SD, Lehne G, Heimdal K, Theodorsen L. Clinical and biochemical long-term toxicity after postoperative cisplatin-based chemotherapy in patients with low-stage testicular cancer. Oncology 1995;52:300-5.

43 Evans TR, Harper CL, Beveridge IG, et al. A randomised study to determine whether routine intravenous magnesium supplements are necessary in patients receiving cisplatin chemotherapy with continuous infusion 5-fluorouracil. Eur f Cancer 1995;31:174-8.

44 Motil KJ, Altchuler SI, Grand RJ. Mineral balance during nutritional supplementation in adolescents with Crohn disease and growth failure. F Pediatr 1985;107:473-9.

45 Berger MM, Cavadini C, Chiolero R, Dirren H. Copper, selenium and zinc status and balances after major traumas. F Trauma 1996;40:103-9.

46 Antilla HM, Salo MS, Kirvela O, et al. Serum trace element concentrations and iron metabolism in allogenic bone marconcentrations and iron metabolism in allogenic bo

47 Itokawa Y. Trace element in long term parenteral nutrition. Nippon-Rinsho 1996;54:172-8. 